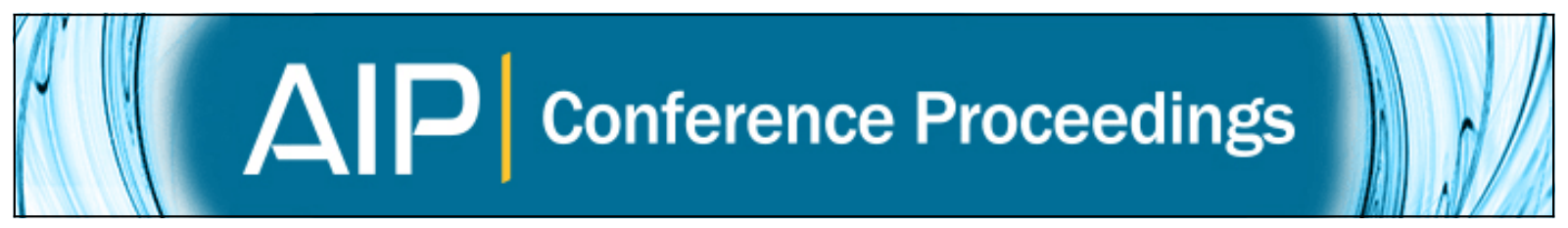

\title{
Comparison of the simulated and LIDAR measured atmospheric density and temperature in lower thermosphere
}

Tian Wan, Guoqing Hu, Jianzheng Jiang, Hongli Liu, Jing Fan, Weilin Pan, and Shuai Qiao

Citation: AIP Conference Proceedings 1628, 1337 (2014); doi: 10.1063/1.4902746

View online: http://dx.doi.org/10.1063/1.4902746

View Table of Contents: http://scitation.aip.org/content/aip/proceeding/aipcp/1628?ver=pdfcov

Published by the AIP Publishing

\section{Articles you may be interested in}

Comparison of balloon-carried atmospheric motion sensors with Doppler lidar turbulence measurements

Rev. Sci. Instrum. 80, 026108 (2009); 10.1063/1.3086432

Rocket-borne instrument for measuring vibrational-rotational temperature and density in the lower thermosphere

Rev. Sci. Instrum. 76, 083101 (2005); 10.1063/1.1988189

A lidar system for measuring atmospheric pressure and temperature profiles

Rev. Sci. Instrum. 58, 2226 (1987); 10.1063/1.1139327

Molecular Beam Techniques Applied to Mass Spectrometric Thermospheric Density Measurements Rev. Sci. Instrum. 44, 1524 (1973); 10.1063/1.1685990

Thermospheric Temperature Measurement Technique

J. Vac. Sci. Technol. 9, 467 (1972); 10.1116/1.1316658 


\title{
Comparison of the Simulated and LIDAR Measured Atmospheric Density and Temperature in Lower Thermosphere
}

\author{
Tian Wan ${ }^{\mathrm{a}}$, Guoqing Hu ${ }^{\mathrm{a}}$, Jianzheng Jiang ${ }^{\mathrm{a}}$, Hongli Liu ${ }^{\mathrm{a}}$, Jing Fan ${ }^{\mathrm{a}}$ \\ Weilin Pan ${ }^{\mathrm{b}}$, Shuai Qiao ${ }^{\mathrm{b}}$ \\ ${ }^{a}$ State Key Laboratory of High Temperature Gasdynamics, Institute of Mechanics, \\ Chinese Academy of Sciences, Beijing 100190, China \\ ${ }^{b}$ Institute of Atmospheric Physics, Chinese Academy of Sciences, Beijing, 100029, China
}

\begin{abstract}
The atmospheric density and temperature in lower thermosphere are analyzed using numerical simulation, empirical model, satellite data and ground LIDAR measurement. The WACCM global atmosphere model is used as the numerical simulation method; the empirical models include NRLMSISE-00 and US-76; the satellite data are taken by US SABER/TIMED satellite. The atmospheric density and temperature with an altitude range from $60 \mathrm{~km}$ to $100 \mathrm{~km}$ at Germu in August 2013 are measured by a ground LIDAR system. Comparison of the results from different methods shows that the density and temperature are in good agreement below altitudes $90 \mathrm{~km}$ and $80 \mathrm{~km}$, respectively. Above the altitudes, the discrepancy between the different methods increases with increasing altitude. It is also noted that the daily and diurnal variation of density and temperature become significant above $100 \mathrm{~km}$ altitude.
\end{abstract}

Keywords: lower thermosphere density and temperature, ground LIDAR measurement, global climate simulation PACS: $92.60 . \mathrm{hv}$, 93.85.Pq, 93.85.Bc

\section{INTRODUCTION}

In recent years, the flight corridor of newly appeared near-space vehicles has reached the lower thermosphere. In order to precisely predict the aerodynamic force on the near-space vehicles, further study of the lower thermosphere is required. Traditional research methods include empirical model [1-3], numerical model [4-16], satellite data [17-23], ground radar observation [24-30], and rocket and balloon [31-33]. However, due to lack of observation data at the lower thermosphere, which is typically beyond reach of both ground-based and satellite radar, study on this atmospheric regime is quite limited. As a result, physical modeling of this layer is difficult. Figure 1 is an example of the uncertainty of the density at $100 \mathrm{~km}$ altitude by using different methods, which shows up to $35 \%$ discrepancy based on US-76 standards.

In this paper, a global climate simulation model, Whole Atmosphere Community Climate Model (WACCM) [16] is used to compute atmospheric density and temperature around $100 \mathrm{~km}$ altitude, and the computed results are compared with LIDAR (Light Detection and Ranging) measurement at Germu in August, 2013. Also compared are the TIMED/SABER (The Sounding of the Atmosphere using Broadband Emission Radiometry), NRLMSISE-00 (Naval Research Laboratory Mass Spectrometer and Incoherent Scatter-00) and US-76 results. In the following sections, the WACCM model is briefly described, followed by introduction of LIDAR measurement. Then the comparison of density and temperature above Germu in August 2013 by using different models are shown.

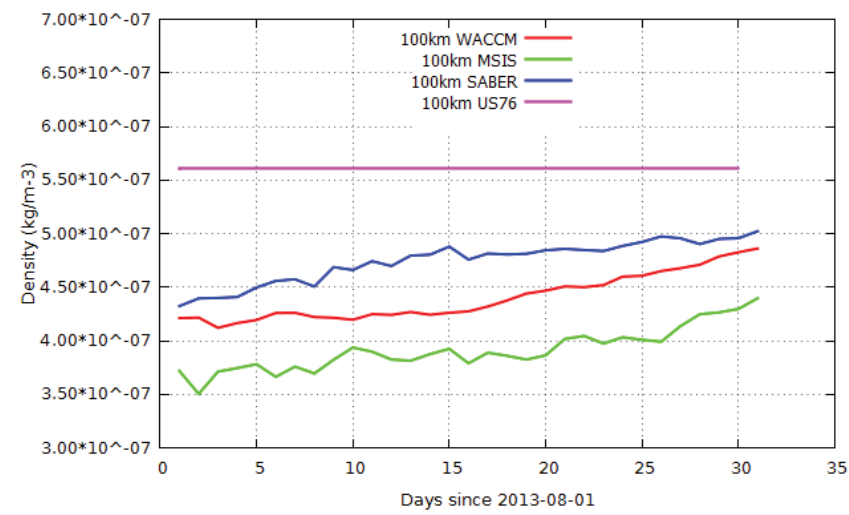

FIGURE 1. Daily density variation predicted by different methods at 100km altitude above Germu in August 2013.

Proceedings of the 29th International Symposium on Rarefied Gas Dynamics AIP Conf. Proc. 1628, 1337-1341 (2014); doi: 10.1063/1.4902746

(C) 2014 AIP Publishing LLC 978-0-7354-1265-1/\$30.00 


\section{WACCM MODEL}

WACCM model is a three-dimensional global climate model developed by National Center of Atmospheric Research in recent years. The latest version, WACCM4, is based on CAM-5.3 (Community Atmosphere Model) atmosphere model, which includes mesosphere/lower thermosphere phenomena, chemistry reactions, dynamic core etc. Numerical methods include finite volume method that is used in this work, spectral element method, etc. From ground to the model top (around 140km), the simulation zone is divided into 66 vertical layers. The vertical resolution is $1.1 \mathrm{~km}$ in troposphere, $1.1 \sim 1.4 \mathrm{~km}$ in lower stratosphere, $1.75 \mathrm{~km}$ at stratosphere top, and $3.5 \mathrm{~km}$ above $65 \mathrm{~km}$. The horizontal resolution is $4^{\circ} \times 5^{\circ}$. The chemistry model being used is the MOZART (Model for OZone And Related chemical Tracers) chemistry model [34]. WACCM4 is based on the NCAR CESM (Community Earth System Model) that is a coupled model including atmosphere, land, ocean and ice modules. CESM version 1.2 is used in this work. The computation starts with standard data F_2000_WACCM on an in-house built Linux cluster using $64 \mathrm{CPU}$.

\section{LIDAR MEASUREMENT}

The Rayleigh laser radar developed by Institute of Atmospheric Physics, Chinese Academy of Sciences was used to measure the density and temperature above Germu $\left(36.25^{\circ} \mathrm{N}, 94.54^{\circ} \mathrm{E}\right)$ in August 2013 . The range of altitude being measured is from $60 \mathrm{~km}$ to $100 \mathrm{~km}$. The wavelength of the radar was $532 \mathrm{~nm}$.

From $30 \mathrm{~km}$ and above, Mie scattering from aerosols is negligible except in some special occasions such as a volcanic eruption. Therefore, by assuming pure molecular scattering in this region, atmosphere temperature can be derived by combining the hydrostatic equation and ideal gas law as

$$
T(z)=T\left(z_{0}\right) \frac{\rho\left(z_{0}\right)}{\rho(z)}+\frac{1}{R} \int_{z}^{z_{0}} g(r) d r \frac{\rho(r)}{\rho(z)},
$$

where $R$ is the gas constant for dry air, $g(z)$ and $\rho(z)$ are the gravitational acceleration and number density at the altitude of $z$, respectively. The seeding temperature $T\left(z_{0}\right)$ at a certain altitude can be adopted from model as the initial estimation.

For Rayleigh scattering, the LIDAR equation for a ground-based LIDAR system is written as

$$
N(z)=\left(\eta T_{A}^{2}\right)\left(\frac{P \Delta t}{h v}\right)\left(\sigma_{R} n(z) \Delta z\right)\left(\frac{A_{R}}{z^{2}}\right)+N_{B},
$$

where $N(z)$ is the total photon numbers received by the telescope of area $A_{R}$ during time interval $\Delta t$ corresponding to a height interval $\Delta z$ in range $\mathrm{z}, N_{B}$ is background noise from solar scattering and PMT dark counts, $\eta$ is system efficiency, $(P \Delta t / h v)$ is the transmitted photon numbers within $\Delta t, \sigma_{R}$ is Rayleigh backscatter cross section, and $T_{A}$ is one-way atmospheric transmittance. Background noise level $N_{B}$ is calculated by averaging photon counts from those bins corresponding to high altitude, where Rayleigh scattering does not occur.

By selecting a reference density at a reference altitude

$$
\rho(z)=\frac{z^{2} \rho\left(z_{0}\right)\left(N(z)-N_{B}\right)}{z_{0}^{2}\left(N\left(z_{0}\right)-N_{B}\right)}
$$

In our measurement, $50 \mathrm{~km}$ is chosen as the reference altitude.

\section{Germu Experiment and Discussion}

LIDAR measurement was conducted at Germu in August 2013, and the measured density and temperature are compared with those from WACCM, SABER, and NRLMSISE-00. Figure 2 plots the vertical density and temperature distribution, where the results of NRLMSISE-00, WACCM and SABER are monthly average in August 2013, and LIDAR result is on August $29^{\text {th }}, 2013$. The theoretical upper limit of SABER is $110 \mathrm{~km}$, but the available data is a little lower. The density distributions show that the results below $90 \mathrm{~km}$ altitude are in good agreement, whereas above $90 \mathrm{~km}$, the discrepancy between the five methods increases substantially, especially for LIDAR, which indicates increased error of LIDAR above $90 \mathrm{~km}$. The temperature distributions show that the results below $80 \mathrm{~km}$ altitude are in good agreement, whereas above $80 \mathrm{~km}$, the discrepancy increases. Note that at $110 \mathrm{~km}$ altitude, the temperature result of WACCM and SABER are higher than NRLMSISE-00 and US-76 temperature, and the reason might be that $110 \mathrm{~km}$ is near the upper limit of WACCM and SABER. 


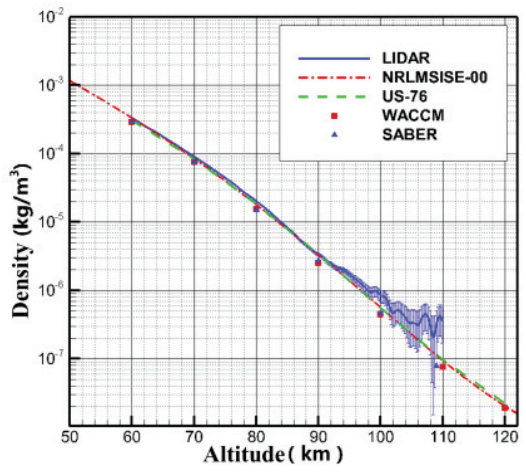

(a) Density

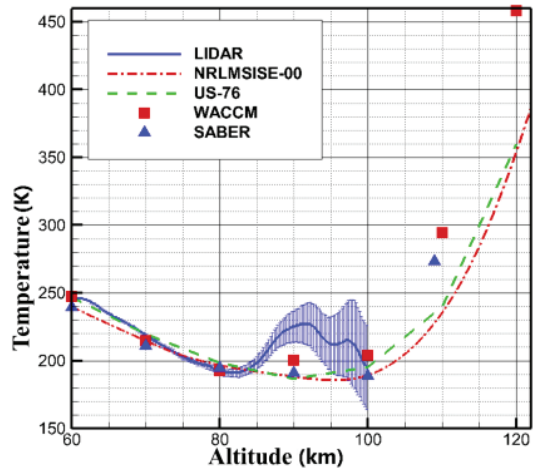

(b) Temperature

FIGURE 2. Atmospheric density (a) and temperature (b) distribution above Germu in August 2013. The results of NRLMSISE-00, WACCM and SABER are monthly averaged, and LIDAR result is on August 29 ${ }^{\text {th }}, 2013$.

Figure 3 is the daily density and temperature variation at $110 \mathrm{~km}$ altitude, where WACCM and NRLMSISE-00 results are at local time 00:00, and local time of SABER is variable. The density distributions show large error of LIDAR at this altitude. The temperature distributions show same decreasing trend of NRLMSISE-00, WACCM and SABER. Note that the zigzags of SABER temperature are due to variable daily local time of TIMED satellite. Figure 4 is the daily density and temperature variation at $100 \mathrm{~km}$ altitude. The density distributions of NRLMSISE-00, WACCM and SABER are in similar trend, whereas the error of LIDAR density is still large at this altitude. Similar trend is also observed in the temperature distributions. Figure 5 is the daily density and temperature variation at $90 \mathrm{~km}$ altitude, which shows smaller discrepancy of density, whereas difference in temperatures of different models is still relatively large.

Among these results, the SABER measured temperature is the most reliable source. At around 110km altitude, NRLMSISE00 and US76 under-predict temperature, which shows loss of accuracy of these two models at this altitude. $110 \mathrm{~km}$ is near the top boundary of the WACCM model which may lead to loss of accuracy and the over-predicted temperature at $110 \mathrm{~km}$ altitude.

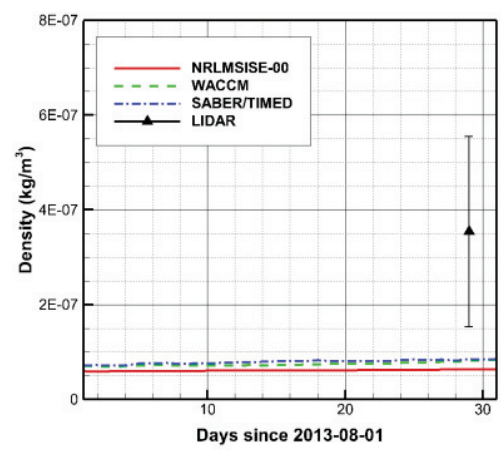

(a) Density

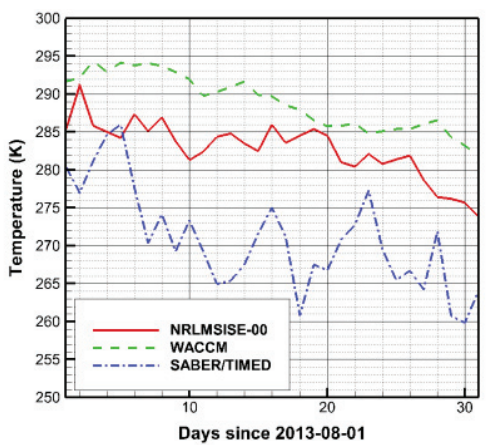

(b) Temperature

FIGURE 3. Daily variation of density (a) and temperature (b) at 110km above Germu in August 2013.

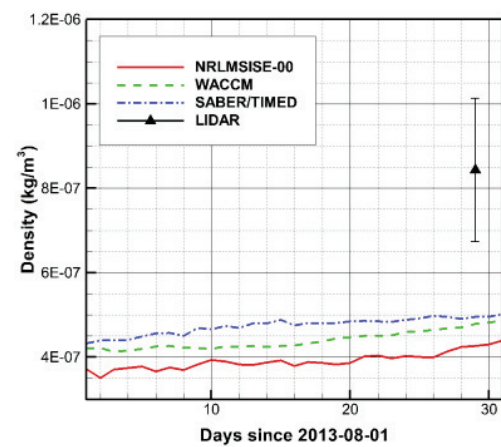

(a) Density

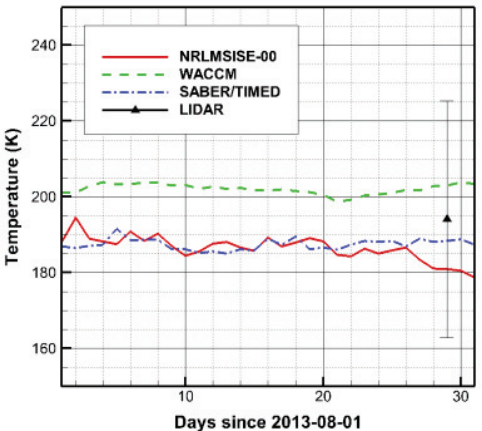

(b) Temperature

FIGURE 4. Daily variation of density (a) and temperature (b) at 100km above Germu in August 2013. 


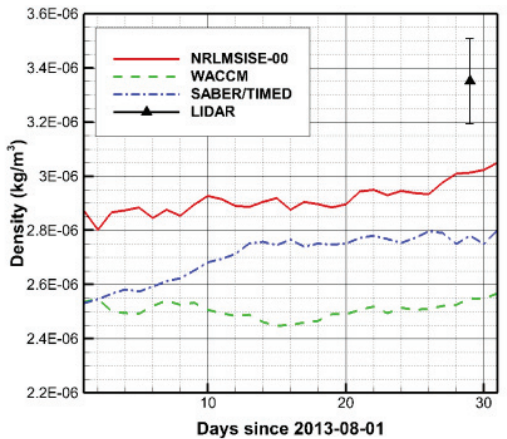

(a) Density

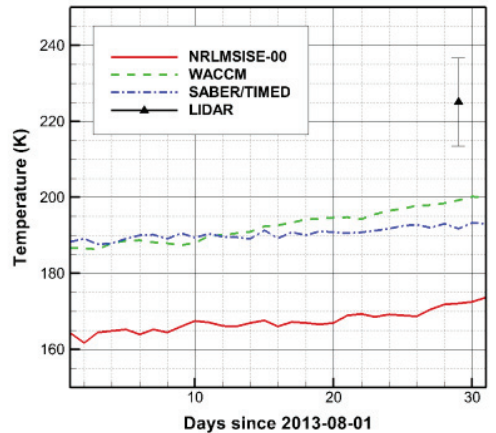

(b) Temperature

FIGURE 5. Daily variation of density (a) and temperature (b) at 90km above Germu in August 2013.

\section{CONCLUSIONS}

The atmospheric density and temperature in lower thermosphere are not well studied. In this paper, the atmosphere at around $100 \mathrm{~km}$ altitude above Germu in August 2013 is studied, by using a global climate model WACCM and LIDAR measurement, as well as comparison with empirical models and satellite data. Comparison shows that the densities from the different methods agree for altitudes below $90 \mathrm{~km}$, and the temperatures agree for altitudes below $80 \mathrm{~km}$. Above these two altitudes, the discrepancy between different methods increases with increasing altitude. Daily variation of density and temperature in August 2013 is plotted, and the trends agree in general, whereas discrepancy increases as altitude increases.

\section{REFERENCES}

1. A Hedin, Journal of Geophysical Research, 92, 4649-4662 (1987).

2. A Hedin, Journal of Geophysical Research, 96, 1159-1172 (1991).

3. J M Picone, A E Hedin, D P Drob, A C Aikin, Journal of Geophysical Research, 107, 1-16 (2002).

4. R E Dickinson, E C Ridley, R G Roble, Journal of Geophysical Research, 86, 1499-1512 (1981).

5. R E Dickinson, E C Ridley, R G Roble, Journal of the Atmospheric Sciences, 41, 205-219 (1984).

6. R G Roble, E C Ridley, R E Dickinson, Journal of Geophysical Research, 92, 8745-8758 (1987).

7. R G Roble, E C Ridley, A D Richmond, R E Dickinson, Geophysical Research Letters, 15, 1325-1328 (1988).

8. A D Richmond, E C Ridley, R G Roble, Geophysical Research Letters, 19, 601-604 (1992).

9. R G Roble, E C Ridley, Geophysical Research Letters, 21, 417-420 (1994).

10. W Wang, Journal of Atmospheric and Solar-Terrestrial Physics, 61, 385-397 (1999).

11. T J Fuller-Rowell, D Rees, Journal of the Atmospheric Sciences, 37, 2545-2567 (1980).

12. T J Fuller-Rowell, D Rees, Planetary and Space Science, 31, 1209 (1983).

13. D Rees, T J Fuller-Rowell, Planetary and Space Science, 36, 935 (1988).

14. D Rees, T J Fuller-Rowell, Advances in Space Research, 10, 83-102 (1990).

15. M J Harris, N F Arnold, A D Aylward, Annals of Geophysics, 20, 225-235 (2002).

16. R R Garcia, Journal of Geophysical Research 112, 1-23 (2007).

17. The Solar Mesosphere Explorer, 2014, see http://lasp.colorado.edu/sme.

18. Upper Atmospheric Research Satellite (UARS) Project Scientific Office Page, 2014, see http://umpgal.gsfc.nasa.gov.

19. C A Reber, etc, Journal of Geophysical Research, 98, 10643-10648 (1993).

20. Earthnet Online, European Space Agency, 2014, see http://earth.esa.int/object/index.cfm.

21. TIMED: A mission to explore one of the last frontiers in Earth's atmosphere, 2014, see http://www.timed.jhuapl.edu.

22. ESA missions, Envisat, 2014, see http://envisat.esa.int/.

23. Goddard Space Flight Center, Aura's HQ Homepage, 2014, see http://aura.gsfc.nasa.gov.

24. F Q Li, etc, Chinese Journal of Space Science, 22, 65-71 (2002).

25. J G Xiong, F Yi, Chinese Journal of Space Science, 4, 318-323 (2001).

26. T E Van Zandt, Annales Geophysicae, 18, 740-749 (2000).

27. S Fukao, etc, Radio Science, 25, 477-485 (1990).

28. J H Qiu, etc, Chinese Journal of Space Science, 4, 318-323 (2001).

29. R L Collins, D Thorsen, S J Franke, Journal of Geophysical Research, 102, 16583-16592 (1997).

30. W Pan, S G Chester, G R Raymond, Geophysical Research Letters, 29, 1-4 (2002). 
31. T Abe, etc, "Coordinated rocket and ground-based observations of neutral temperature during the dynamics and energetics of the lower thermosphere in Aurora (DELTA) Campaign" in Amer. Geophys. Uni. Fall meeting, 2005.

32. G T Qin, etc, Chinese Journal of Space Science, 22, 136-141 (2002).

33. G T Qin, etc, Chinese Journal of Space Science, 23, 135-141 (2003).

34. L K Emmons, etc, Geoscientific Model Development, 3, 43-67 (2010). 